\title{
TOWARDS A DIGITAL ARCHITECTURAL HERITAGE KNOWLEDGE MANAGEMENT PLATFORM: PRODUCING THE HBIM MODEL OF BAIT AL NABOODAH IN SHARJAH, UAE
}

\author{
R. SABRI ${ }^{1 *}$, S. B. ABDALLA ${ }^{1}$ AND M. RASHID ${ }^{1}$ \\ Architectural Engineering Department \\ University of Sharjah \\ University City, Sharjah, United Arab Emirates (UAE) \\ e-mail: rsabri@sharjah.ac.ae (*corresponding author), \\ sabdalla@sharjah.ac.ae,_mrashid@sharjah.ac.ae http://www.sharjah.ac.ae
}

Keywords: Heritage documentation, HBIM, terrestrial laser scanning, scan-to-BIM, point cloud data, Bait Al Naboodah Museum

\begin{abstract}
This paper explores the methodology for the production and integration of Heritage Building Information Modeling (HBIM) into the museum management system of the Emirate of Sharjah, United Arab Emirates (UAE). The historic Bait Al Naboodah Museum is documented as a pilot study using terrestrial laser scanning (TLS) technology. The scanning and modelling processes are explained in a seven-stage workflow: preliminary data acquisition, site surveying and terrestrial laser scanning, processing of the captured cloud point data, post-processing and modelling, quality control, final delivery of the digital model, and its validation. The architectural elements and details of Bait Al Naboodah have been reconstructed in a multilayered 3D digital model, and its accuracy has been tested. This HBIM model has been conceived as the basis of a shared inter-institutional platform for the Museum's management.
\end{abstract}

\section{INTRODUCTION}

Finding innovative tools for the documentation and conservation of increasingly broad heritage portfolios has dominated heritage conservation research agendas since the beginning of the 21 st century. Recently research has focused on various aspects of the configuration and utilisation of digital applications in heritage management ${ }^{[1]}$. Heritage Building Information modelling (HBIM) has emerged as a significant architectural heritage recording and conservation management tool ${ }^{[2,3,4,5]}$. Studies from different geographic contexts have revealed important insights regarding the documentation, integration and management of heterogeneous data in digital models ${ }^{[6,7]}$. However, this has remained an under-researched heritage topic in the UAE.

The built heritage of the United Arab Emirates consists of examples of traditional architecture of residential, defence, commercial and educational functions, roughly dating from 
the early 19th to mid-20th century. The heritage authorities of the Emirate of Sharjah have restored many heritage structures since the 1990s. Many of them are adaptively reused. Several such structures have been re-purposed as museum spaces under the management of the Sharjah Museums Authority (SMA). The conservation management of these structures is the responsibility of the Sharjah Archaeology Authority (SAA). Interviews with relevant officials have revealed that managing museums in heritage structures is challenging as there are multiple tasks and responsibilities. Institutions carry out planning related to conservation management, facilities management, and exhibition management. As these institutions follow a traditional management style, each one has unique documentation and planning methodologies.

While de-centralisation in heritage management has many advantages, overlapping interinstitutional planning for different activities is unavoidable. Clashes in exhibition planning, maintenance works for building services, and conservation works, which disrupts scheduled activities, are examples. Other practical issues include duplication of data by each stakeholder for their institutional requirements. Consequently, resources are wasted to reproduce new architectural drawings or locate existing ones in dispersed archives. It should also be noted that standard sets of architectural drawings of heritage structures are either manually or digitally drawn based on manual measurements; they typically include little detail. Therefore, when architectural data for a part of the building, which is not visible on a standard set of architectural drawings, is required, the technicians need to go back to the building to take new measurements. This happens, for instance, when an exhibitor needs accurate scaled drawings of an exhibition space to plan an exhibition. This research explores the methodology and technical issues for
developing a digital model as an effective management platform, where heritage data will be
conceptualised and categorised in a semantically enriched system. The research uses Baif al
Naboodah Museum in Sharjah as the pilot study. It investigates the methodology of producing
an HBIM to be used as a shared management platform by the stakeholder institutions relating
to museums in heritage structures.

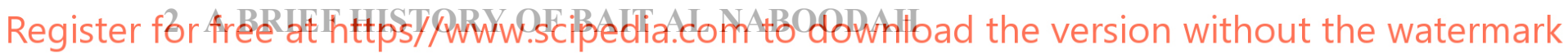

Bait Al Naboodah is the oldest and largest surviving traditional courtyard house in Sharjah. This house was originally constructed in c.1845 by Obaid bin Eissa Bin Ali Al Shamsi (aka Ai Naboodah), a prominent pearl merchant with international commercial ties ${ }^{[8]}$. Alazawi notes that there are at least two main construction phases for this partially two-storied courtyard-plan type house: the main entrance and rooms on the East façade as well as the stairs on the North and South which were built in the first stage ${ }^{[9]}$. This was followed by adding rooms on the other sides of the courtyard and the second floor in several phases of the second stage as the Al Naboodah family grew.

Bait Al Naboodah was subjected to an extensive restoration project from 1990-1995, and it was opened as an ethnographic museum in 1995. Soon after that, the building required extensive conservation work due to continuing material deterioration problems caused by a high water table and termite damage. The building was waterproofed and termite proofed during the conservation works. The work was finalised in 2016, and the museum subsequently reopened (Figure 1). The building was also retrofitted with fire detectors, CCTV, air conditioning, and ramps. Currently, while the SMA manages the museum, the SAA is responsible for its conservation management. The aim of this research is to create an HBIM to be populated with 
architectural heritage data and shared by the stakeholder institutions to inform the management of the museum, conservation, and building facilities.
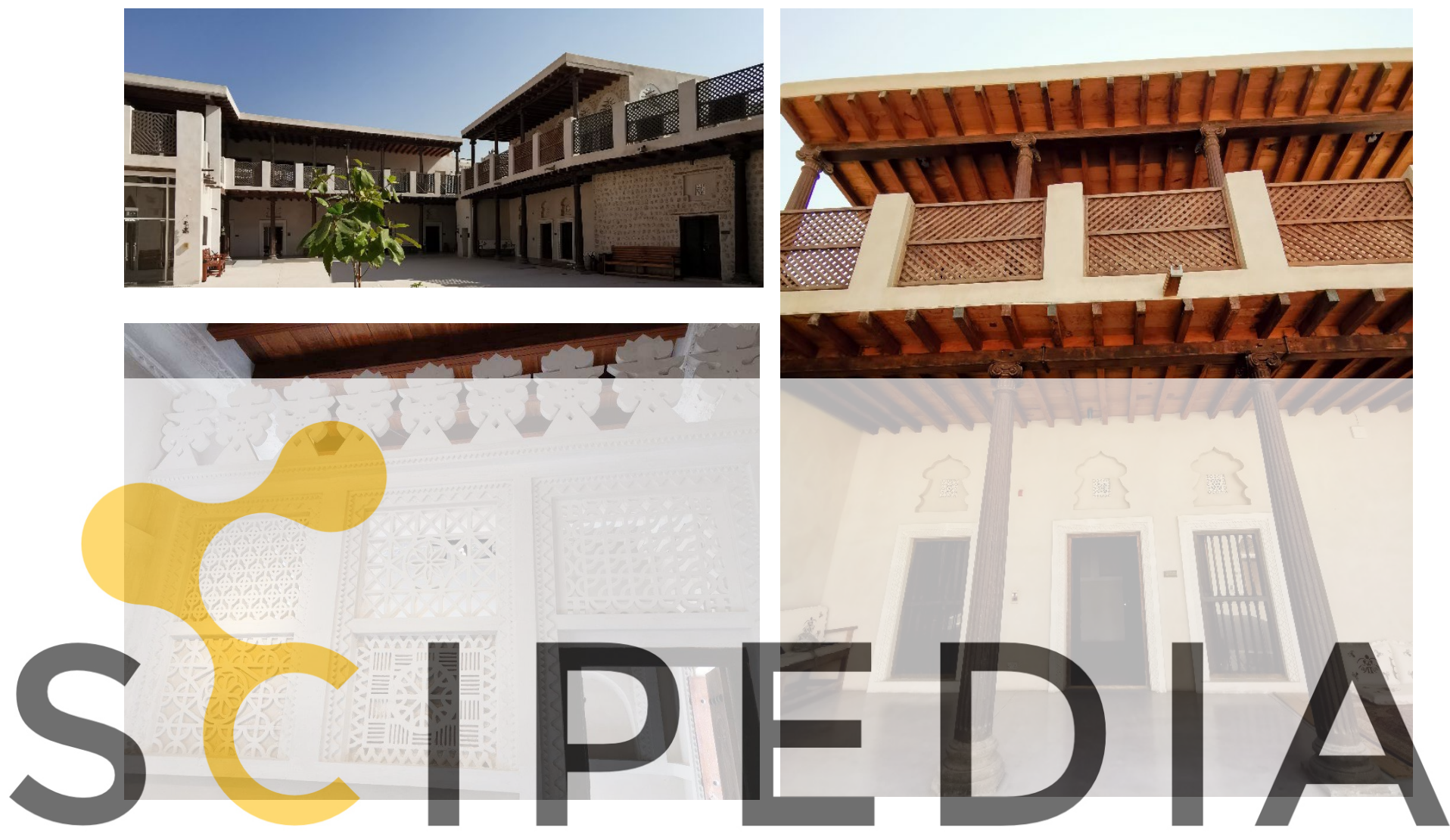

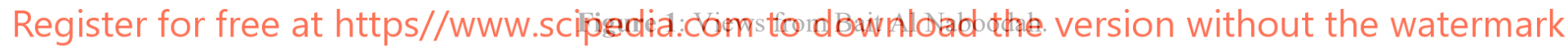

\section{DATA ACQUISITION, PROCESSING, AND MODELING}

This research utilises terrestrial laser scanning (TLS), also known as terrestrial light detection and ranging (LiDAR), for the architectural documentation of Bait Al Naboodah. TLS measures distance remotely by emitting laser pulses at target points. It is 'regarded as mass data collection technique capable of rapidly collecting millions of points,' making it suitable for generating accurate data ${ }^{[10,11,12]}$. The data collection and processing methodology and workflow is described in the following.

\subsection{HBIM methodology and workflow}

The process started with acquiring permission from SMA to laser scan Bait Al Naboodah. It continued with site visits in coordination with the SMA officials regarding the scanning process, surveying the heritage structure, and planning for scanning and model making resources. TLS has been planned following SMA's health and safety policy. The workflow is presented in Table 1. 
Table 1: Data gathering, processing, modelling, and validation stages.

\section{Process}

Stage

1. Site visit and
preliminary data
acquisition
captured point cloud data
Pre-study site visits for planning the scanning requirements and coordinating with SMA authorities regarding permission processes.

Spatial data gathering through TLS.

Capturing high-quality three-dimensional image of the surroundings in the form of Red Green Blue (RGB) coloured point cloud data.

Transferring the point cloud data to a computer environment and initiating the point clouds' cleaning process.

Modifications and preparing the point cloud data for further processing.

Transferring point cloud data into Autodesk Revit.

Mapping HBIM objects onto point-cloud.

Converting the point cloud data into mesh objects.

Using Cyclone plugin for Revit to alignment and fitting the image

data on the scan data in Revit.

Creating customised objects as families in Revit.

Investigating and verifying factors affecting the quality of point cloud data.

Quality Control (QC)
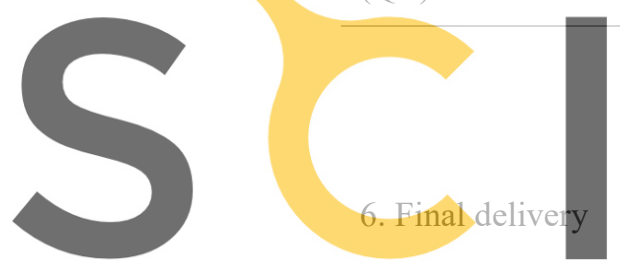
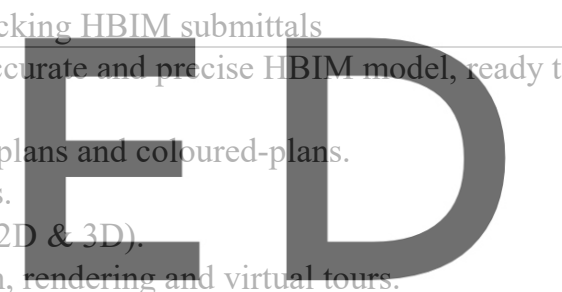

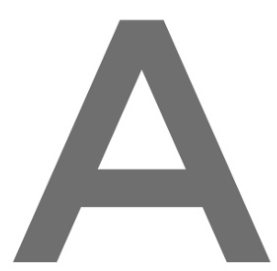

- Maintenance schedules (doors, windows, rooms,

Register for free at https//www.scipedia.duphs tofc download the version without the watermark - Bill of quantity/cost estimates.

Site visit for validating the model through;

7. Validation

- Visual inspection of functions and spaces.

- Random validation of measurements and dimensions.

\subsection{Terrestrial laser scanning}

We used a single 3D scanner for the TLS, and this means the tripod scanner had to be moved to several locations to capture the larger site from various angles (Figure 2). Therefore, the entire project has been captured using a single tripod-mounted scanner, namely the FARO 3D model X130, which has a scanning range of $130 \mathrm{~m}$. Although using a single scanner slowed down the scanning process, we finalised the scanning in two working days (27-28 October 2019). The chosen $3 \mathrm{D}$ laser scanner captures up to one million measurement points per second and generates a precise, high-quality three-dimensional image of its surroundings using an integrated camera. The point cloud data captured by the 3D scanner is a collection of points converted from a range of angular measurements into a common Cartesian (XYZ) coordinate 
system and precisely defines the surfaces of the scanned object ${ }^{[13,14]}$. The scanner's integrated camera captures high-quality three-dimensional images of its surroundings. However, it produces only one three-dimensional image for each scan, despite each scan containing millions of cloud points. This single image (Figure 2) gives the object the RGB colour, resulting in colourised point clouds.

\subsection{Transferring point cloud data and post-processing}

The captured point cloud data is a collection of $3 \mathrm{D}$ coordinate systems representing the building's exterior surface, including its geometry and colour. After the scanning process, this data has been transferred to a computer environment. However, the captured 3D point clouds are considered raw data at this stage. During the processing stage, the colour of the object surfaces has been added by overlaying imagery from the scanner's integrated camera via Cyclone plugin for Revit (Figure 2).

Usually, further modifications are necessary to prepare for the finished HBIM model. For instance, the point clouds have to be cleaned if there are scan vibrations or dust particles on the lens that may scatter the point cloud data. However, in our case, there were no major issues, except that the surrounding buildings required some cleaning. For our project, the 3D scanner was equipped with an integrated camera to capture high-quality images to aid in point cloud interpretation and provide colourised point clouds (Figure 2).
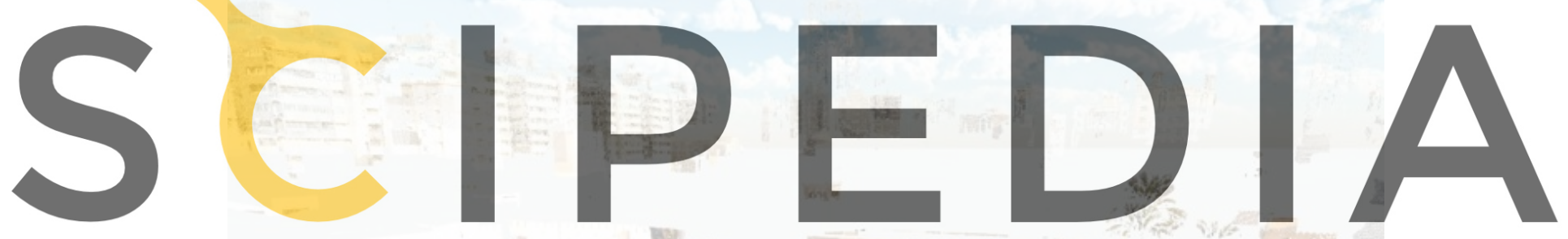

Register for free at https//www.scipedia.com to download the version without the watermark

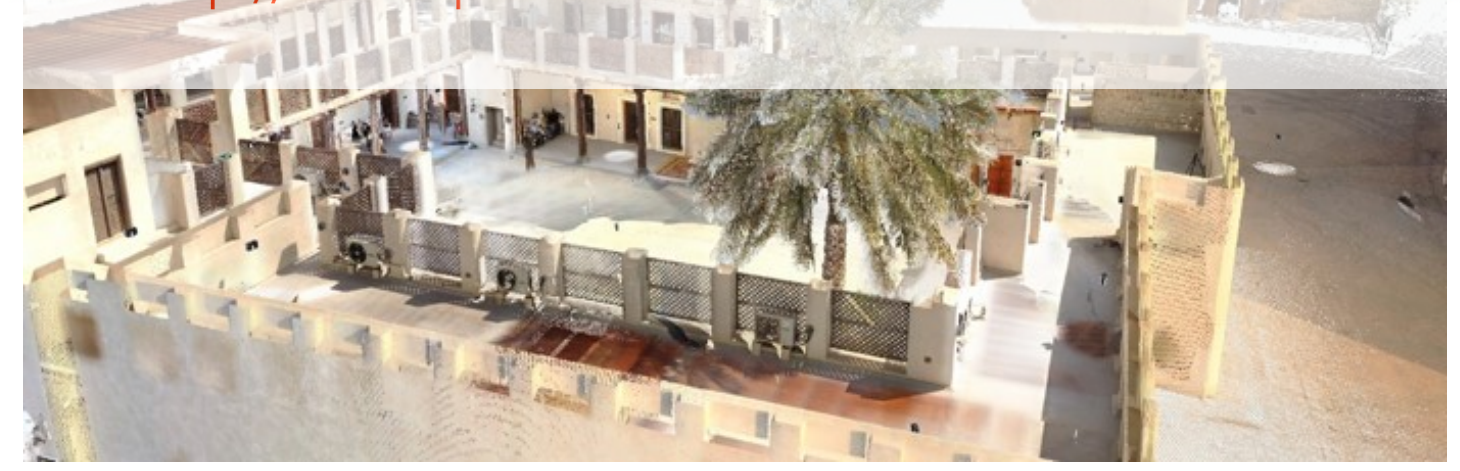

Figure 2: Colorized Point clouds by RGB color.

\subsection{Modeling and mapping HBIM objects onto the point-cloud}

The modeling/ mapping processes continued with converting the point cloud data into mesh objects. We built the 3D model of Bait Al Naboodah in Autodesk Revit with the assistance of 'Cyclone plugin for Revit'. This aided in depicting the existing heritage geometry of the 
architecture of the heritage structure and producing 3D datasets of the heritage asset in a 3D BIM. However, we had to do some organisations on the point cloud data prior to this stage for the necessary smoothing and proper integrations within the HBIM.

During the 3D modelling process, some objects such as walls, columns, or beams and some doors and windows could be imported directly from Revit libraries. Some others were edited to capture the actual geometric conditions of Bait Al Naboodah. However, due to the complex, non-parametric geometries typically associated with heritage buildings, the digitalisation process involved modelling and customising several objects developed explicitly for this project. Electrical fixture such as lights and lanterns, windows and windows quads, furniture and decorative elements, as well as profiles from roof and facade details, stairs, handrails, and columns, are among the custom created elements for this project (Figure 3). Similarly, some material surfaces had to be created for the project as they were not in the standard Revit libraries (Figure 4).

The customised objects are generated in the same way that existing Revit library objects, i.e. as families. As a result, an object in Revit is associated with a specific family that yields subelements, known as classes. For example, all windows have been categorised under one family that branches to various windows (i.e. double light windows, single windows, and top windows). The same has been applied to doors, walls, floors, and decorative elements/details.
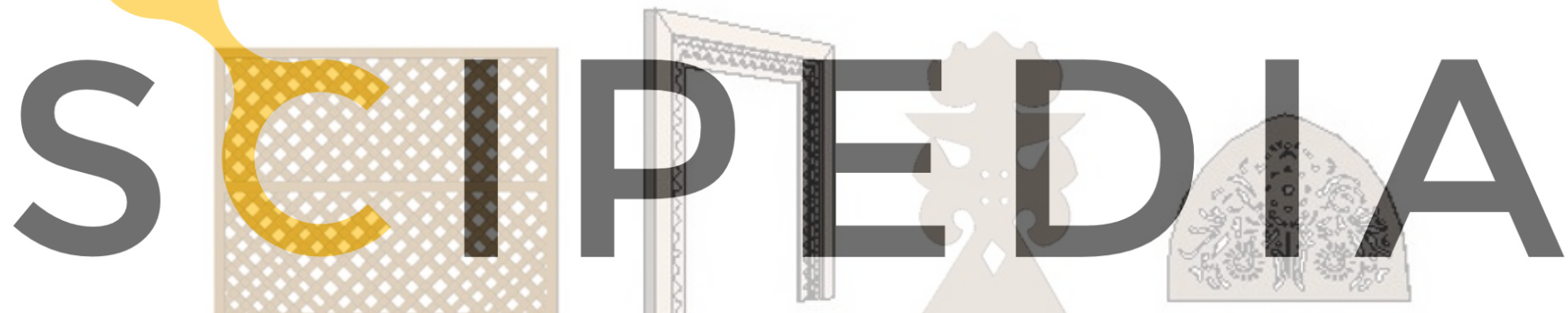

Register for free at https//www.scipedia.com to download the version without the watermark

Figure 3: Examples from customised architectural elements created specifically for Bait Al Naboodah HBIM model.
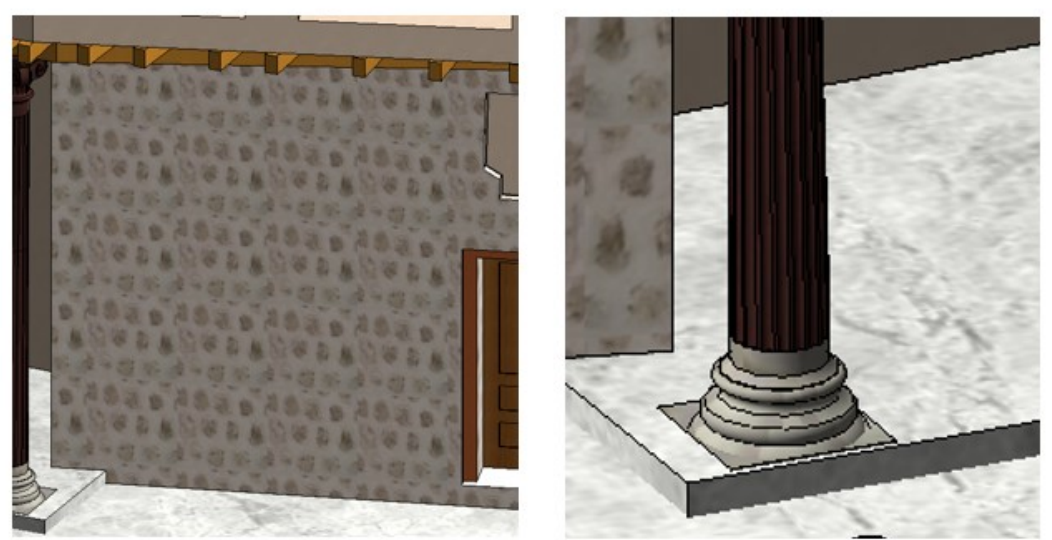

Figure 4: Examples from customised material and mats created specifically for Bait Al Naboodah HBIM model. 


\subsection{Quality Control (QC)}

We investigated and verified the factors that affect the quality of TLS point cloud data at this stage. We verified the HBIM's credibility by point cloud validation, geometry, clash detection, and model coordination. In addition, we reviewed the HBIM model to ensure compliance, accuracy, and a high-quality deliverable to validate the collected data. Revit 2020 allowed for visualisation, walkthroughs, sectioning the model, and the development of plans and schedules. Additionally, Navisworks Manage 2020 was helpful in further reviewing the HBIM's integrity and precise visualisation and review. The QC also included a review of the point cloud data generated by the FARO SCENE LT 2019.2 software. During the QC process, we detected the absent elements and inconsistencies such as a lack of finish material on some façades, missing wood from the ceiling, and missing fixtures and furniture.

\subsection{Final HBIM delivery and validation}

After correcting the missing parts and modifying the inconsistencies, the final 3D model contained all of the building's architectural components, electrical fixtures, and mechanical components (AC units and toilet fixtures). At this stage, a complete set of floor plans (2D \& $3 \mathrm{D}$, elevation, sections (2D \& 3D), as well as doors, windows, rooms and columns schedules were generated from the model (Figures 5-7).

We continued verifying its accuracy and precision by taking in-situ measurements and comparing them with the scaled drawings generated from the HBIM model. The validation

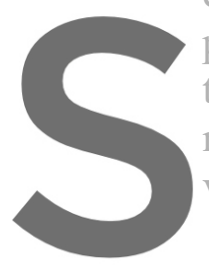
process was based on ta
testing horizontal and
measurements showed ac
very consistent and adcur
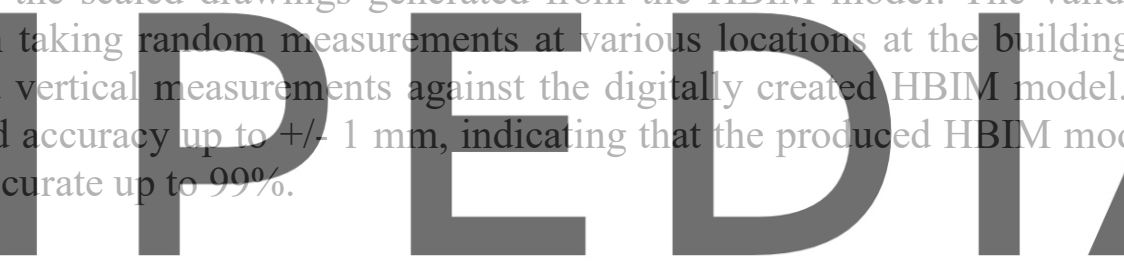

Register for free at https//www.scipedia.com to download the version without the watermark

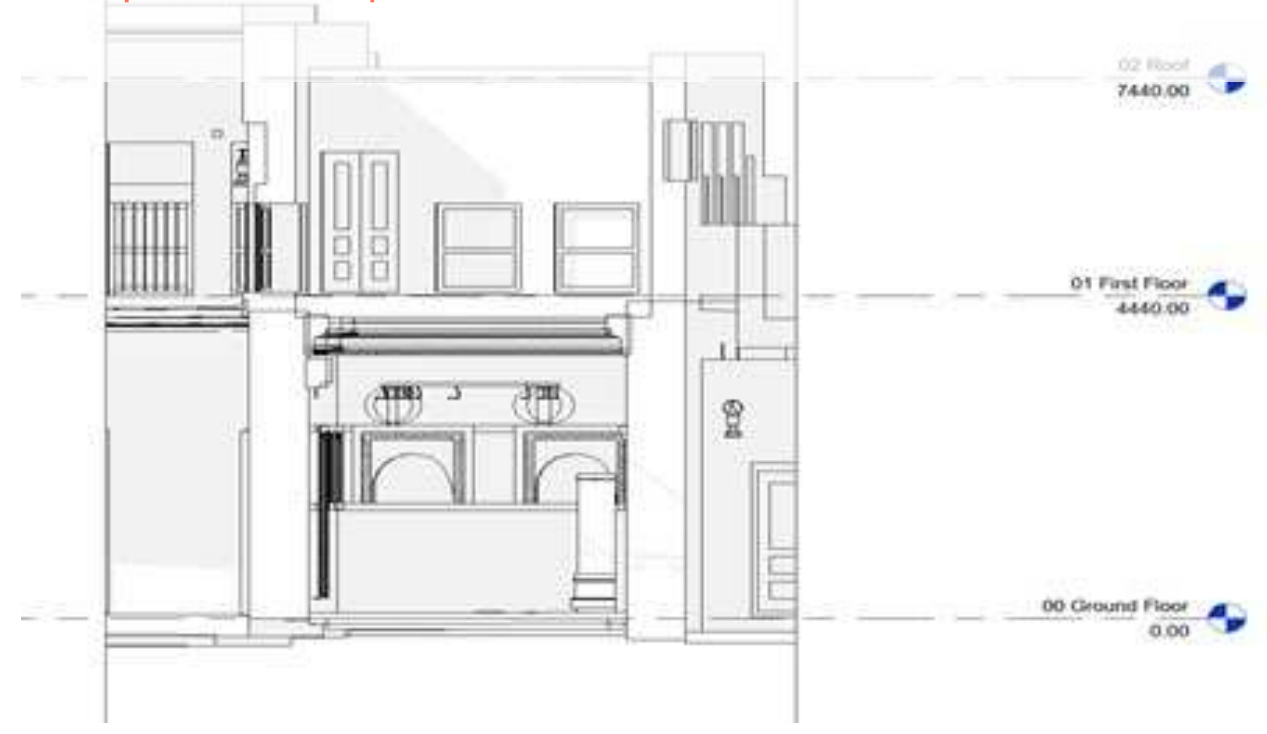

Figure 5: An elevation generated from Bait Al Naboodah HBIM. 


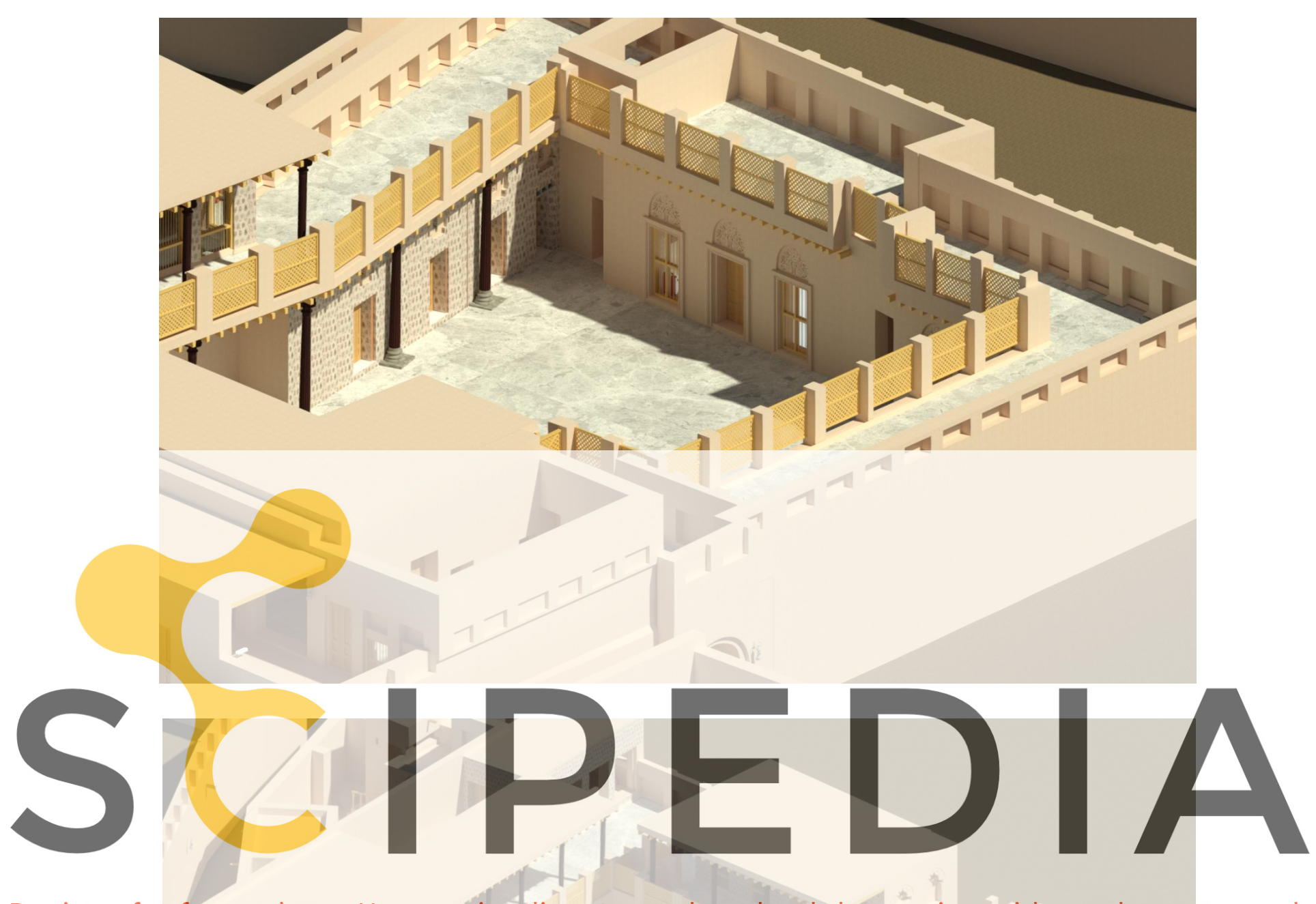

Register for free at https//www.scipedia.com to download the version without the watermark

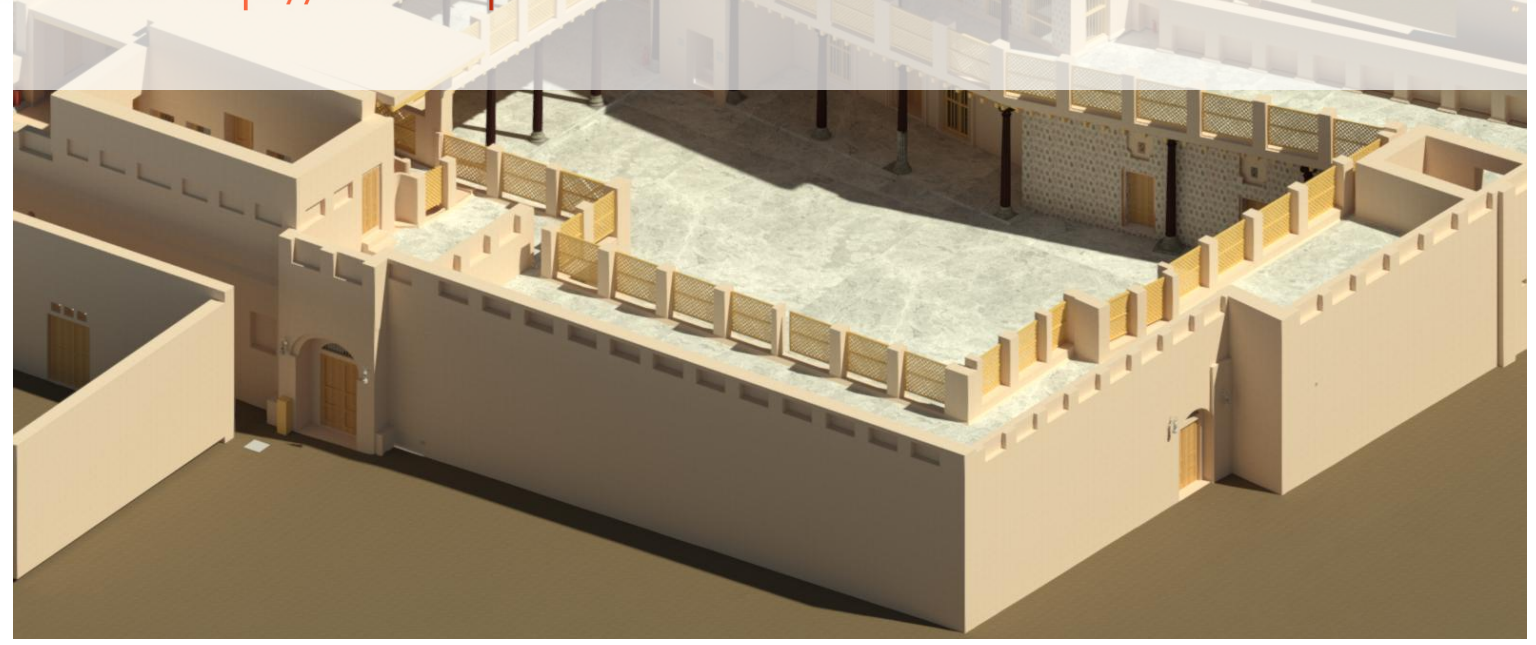

Figure 6: 3D images of the building, generated from Bait Al Naboodah HBIM. 


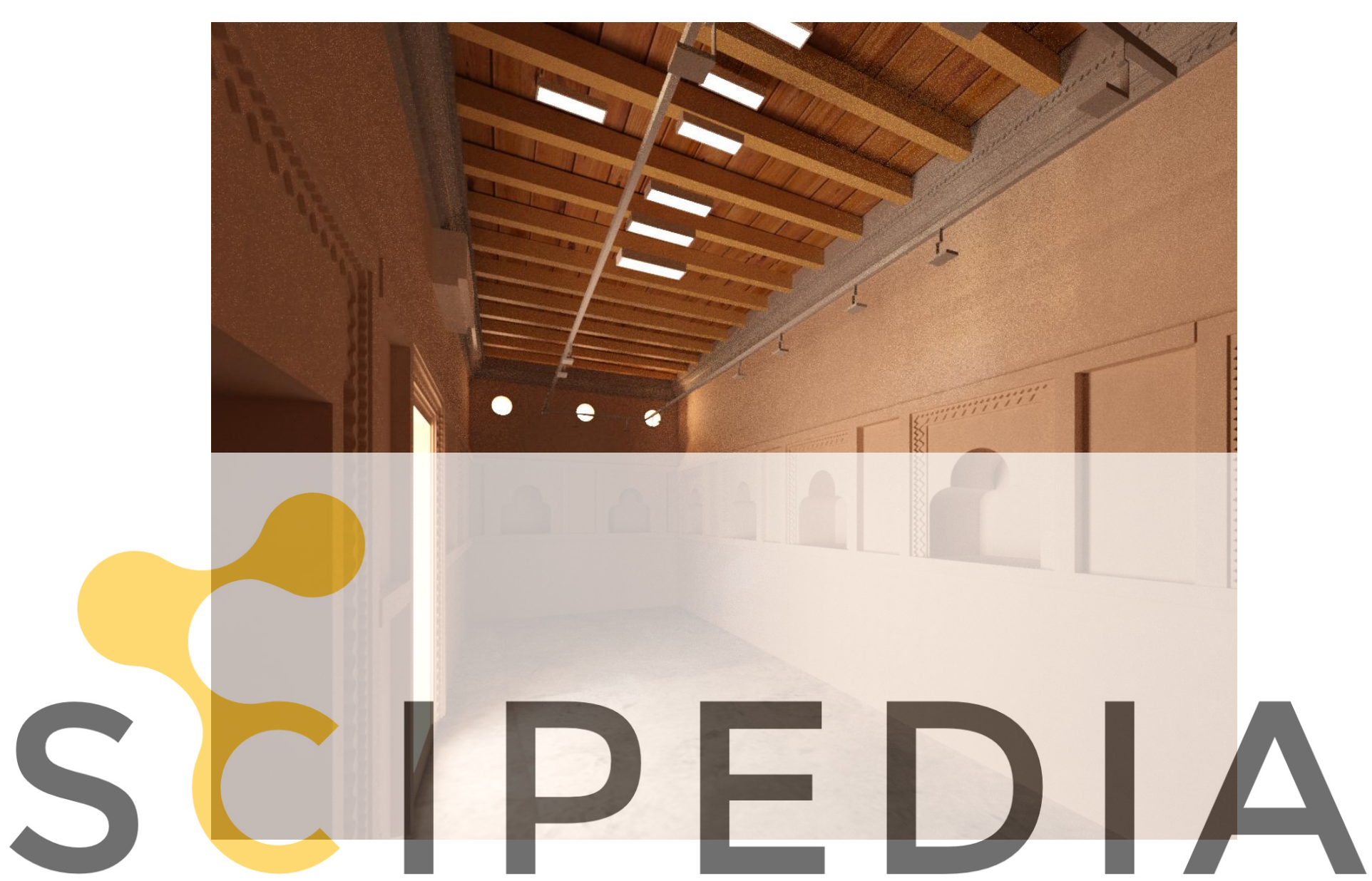

Figure 7: Interior of a temporary exhibition space, generated from Bait Al Naboodah HBIM.

Register for free at https//www.scipedia.com to download the version without the watermark 5 CONCLUSION

3D laser scanning and digital architectural heritage knowledge modelling are relatively expensive compared to traditional manual documentation systems. Not only laser scanners are costly, but the scanning and transferring of captured point could data to a computer environment, and its conversion into architectural drawings requires specialised knowledge and expertise. This technology is not widely tested on the heritage structures in the UAE. Our investigation has revealed that the output is invaluable in generating accurately scaled plans, sections, and architectural details for any space and in any numbers. The HBIM, produced for Bait Al Naboodah, using the scan-to-BIM methodology, has proven to be an accurate and efficient architectural documentation method. Scan-to-BIM technology and expertise are available in the UAE's booming construction sector, and this can be efficiently utilised in the heritage sector. The next step of this project is the population of the HBIM model with data to convert it into an inter-institutional digital platform to be used for the management of museum, conservation and building facilities.

Acknowledgements. This research has been financially supported by the University of 
Sharjah Research Grant Ref. V.C.R.G. / R. 438/2019. The authors would like to thank the Sharjah Museums Authority and Bait Al Naboodah Museum officials for their support during the laser scanning.

\section{REFERENCES}

[1] Arayici, Y., Counsell, J., Mahdjoubi, L., Nagy, G. A., Hawas, S., and Dweidar, K. (Eds.). Heritage building information modelling. Routledge (2017).

[2] Quattrini, R., Pierdicca, R. and Morbidoni, C. Knowledge-based data enrichment for HBIM: Exploring high-quality models using the semantic-web. J. of Cultural Herit. (2017) 28: 129-139.

[3] Jordan-Palomar, I., Tzortzopoulos, P., García-Valldecabres, J., and Pellicer, E. Protocol to Manage Heritage-Building Interventions Using Heritage Building Information Modelling (HBIM). Sustainability (2018) 10, 908.

[4] Bruno, N. and Roncella, R. HBIM for Conservation: A New Proposal for Information Modeling. Remote Sens. (2019) 11, 1751.

[5] Andriasyan, M., Moyano, J., Nieto-Julián, J.E., \& Antón, D. From Point Cloud Data to Building Information Modelling: An Automatic Parametric Workflow for Heritage. Remote Sens. (2020) 12, 1094.

[6] Tucci, G., Conti, A., Fiorini, L., Corongiu, M., Valdambrini, N., and Matta, C. (2019). M-

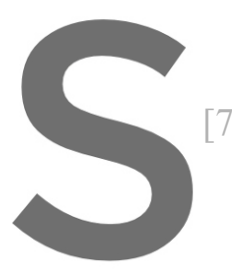
BIM: a new tool for the Galleriadell' Accad
10(21): 40-55.
López, F. J, Lerones, P. M., Llamas, J., Góm
Framework for Using Point Cloud Data of
Modeling in A BIM Context: A Case Study
Int. J. Arch. Her. (2017) 11 (7): 965-986.
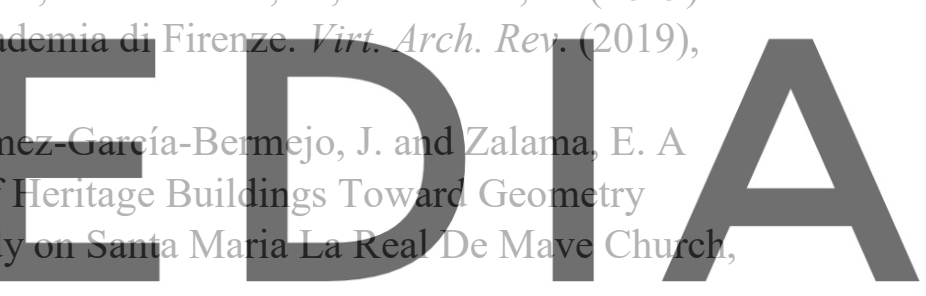

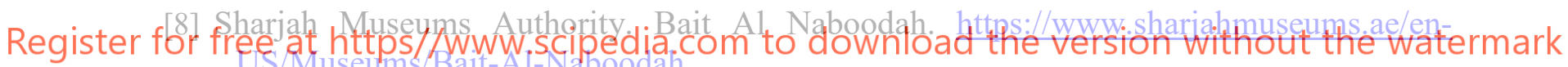

[9] Alazawi, A.S. Sharjah Institute for Heritage, Sharjah, UAE. Personal communication, 16 September 2019.

[10] Rocha, G., Mateus, L., Fernandez, J. and Ferreira, V., 2020. A Scan-to-BIM Methodology Applied to Heritage Buildings. Heritage. (2020) 3(1): 47-67.

[11] Boardman, C. 3D Laser Scanning for Heritage Advice and Guidance on the Use of Laser Scanning in Archaeology and Architecture. Historic England (2018). https://historicengland.org.uk/images-books/publications/3d-laser-scanning-heritage/

[12] Sztwiertnia, D., Ochałek, A., Tama, A. and Lewińska, P. HBIM (heritage Building Information Modell) of the Wang Stave Church in Karpacz - Case Study. Int. J. of Arch. Herit. (2021). 15(5): 713-727.

[13] FARO (2021) https://www.faro.com/en/Products/Hardware/Focus-Laser-Scanners

[14] Moyano, J., Odriozola, C. P., Nieto-Julián, J. E., Vargas, J. M., Barrera, J. A., and León, J. (2020). Bringing BIM to archaeological heritage: Interdisciplinary method/strategy and accuracy applied to a megalithic monument of the copper age. J. of Cultural. Herit. (2020), 45: 303-314. 